Amazonía Peruana, Volumen XVII, Nº 34, 2021; pp. 79-98

\title{
LA ENFERMEDAD EN LAS COMUNIDADES ASHÉNINKAS EL SUSTO Y EL CHOQUE DE AIRE
}

\author{
Rosendo Gualima Padilla cmf \\ Universidad Católica Boliviana \\ rgualimacmf@yahoo.com \\ (1) https://orcid.org/0000-0002-7789-1740
}

\section{Resumen}

El autor describe los síndromes culturales desde la concepción ashéninka del Alto Ucayali: susto, choque de aire, cutipo, mal de gente, hechicería, brujería, pusanga y berbaje. Luego se centra en la curación de dos de estos: el choque de aire y el susto. Además señala que la salud se concibe no solo como la ausencia de enfermedad, sino como el equilibrio en las relaciones con los espíritus, con la comunidad humana y los difuntos.

Palabras claves: Ashéninka; Salud; Síndromes culturales; Curación

\section{Summary}

The author describes the types of diseases from the Ashéninka conception, cultural syndromes: fright, air shock, cutipo, people's disease, sorcery, witchcraft, pusanga and berbaje. It then focuses on healing two of them, air shock and fright. 
He points out that health is conceived not only as the absence of disease, but as a balance in relations with spirits, with the human community and the deceased.

Keywords: Asheninka; Health; Cultural syndromes; Curing

\section{Introducción}

He tenido la dicha de "estar" casi una década con el pueblo ashéninka, en la Amazonía peruana. Compartiendo muchos momentos de su vida, desde la vida cotidiana donde lo simple transmite sentidos profundos, hasta aquellos momentos más profundos, donde de forma más consciente, realizan su propio ser amazónico. He tenido cierta facilidad para insertarme con el pueblo, lo que no significa que hay sido fácil. Considero que en gran medida porque también soy amazónico, ya que pertenezco al pueblo movima, en el departamento del Beni, en la selva boliviana y porque he llegado abierto para reconocer su sabiduría, su fe.

Este "estar", más que el clásico "ser", en clave de misión abierta que escucha, reconoce, y valora la fe, la esperanza de un pueblo, expresada en su cotidianidad, en sus formas de vivir y sus prácticas en las que manifiesta su identidad profundamente espiritual $-\mathrm{y}$ también con ciertos elementos antropológicos que en los estudios de la carrera he ido desarrollando-, me permite entender distintos aspectos de su vida. Razón por la cual ahora tomaré la parte concerniente a la salud de este pueblo, reflejada en algunas de sus comunidades asentadas a orillas del río Unini, afluente del Ucayali.

En este breve escrito, pretendo, por un lado, presentar una forma de cómo pueden entenderse las enfermedades desde la cosmovisión ashéninka, y, por otro lado, presentar dos experiencias muy personales: el haber estado presente cuando a una adolescente le dio el "choque de aire" y la forma de curar el susto (mal que padecen los niños). Experiencias que poco a poco han ido compartiendo los médicos y especialistas en salud de la selva al verme caminando con ellos.

Para esto realizaré una breve contextualización y ubicación geográfica. Seguidamente abordaré, de manera breve, la cosmovisión ashéninka, con el propósito de hacer entendible la forma de abordar las enfermedades. Luego trataré de clasificar las enfermedades tal como las concibe este pueblo; y por último, abordaré las dos experiencias personales en el campo de la salud, mencionadas en el párrafo anterior.

Para este trabajo, recurriré principalmente a entrevistas, pero ante todo a mi experiencia y reflexión personal; por tanto, escribir es para mí un intento de 
sistematización de lo observado y vivido con el pueblo ashéninka, así como una forma de "compartir" estas experiencias que hasta ahora son muy personales. $\mathrm{Y}$ acaso consideremos esta parte de la sabiduría ancestral de nuestros pueblos, en nuestras reflexiones, proyectos diversos o trabajos; sabiduría con la cual han sobrevivido y siguen sobreviviendo los ashéninkas; una sabiduría que brota de la interrelación del respeto y armonía con los distintos niveles de la creación.

\section{Contextualización}

El pueblo ashéninka se encuentra al centro de la Amazonía peruana, ocupando la selva alta del Gran Pajonal, la parte alta y baja del río Ucayali, así como las riberas de afluentes del mismo (el río Unini, Cohengua), dentro del territorio del actual departamento de Ucayali. Aunque hay que mencionar la existencia de comunidades ashéninkas en otros lugares como Cerro de Pasco, Huánuco, Junín, y el Breu, frontera con Brasil.

Hasta hace poco existía el dilema acerca de la identidad del pueblo ashéninka, pues para algunos era parte del pueblo asháninka o, simplemente, porque el Estado peruano los asumía como asháninkas. El pueblo asháninka, llamado la gran nación asháninka por la cantidad de población, que viene a ser la mayor en la Amazonía peruana, asumía a este grupo, aunque existía el reclamo de que, aunque tenga un tronco común es un pueblo con sus rasgos propios y su historia propia que debe ser considerado como tal y no asumido por los asháninka. Desde mi experiencia, las comunidades ashéninkas se reconocen como diferentes de los asháninkas, tanto en la forma de hablar, que aunque hay palabras que se parecen, no son iguales; en las costumbres, como la forma de preparar el masato y de compartirlo, la forma de tejer la kushma, los colores y diseños que se usan, la forma de pintarse la cara con el achiote, incluso las formas de trabajo. Cuestiones que desde fuera pueden parecer simples, sin embargo, es las que definen y diferencian al indígena.

Hace poco, en mayo del 2019, después de distintas gestiones, el Ministerio de Educación del Estado Peruano, mediante resolución ministerial $\mathrm{N}^{\circ}$ 199-2019-MINEDU, reconoció oficialmente el alfabeto de la lengua ashéninka, reconociendo a estas alturas la existencia de este pueblo.

El pueblo ashéninka ocupó en principio la selva alta del Gran Pajonal del actual distrito de Oventeni, de donde fueron migrando hacia las riberas de los ríos antes mencionados; según parece, por las conversaciones con los más ancianos, esta migración se dio debido a los ríos que proveen los peces, la tierra 
más generosa para los cultivos de yuca y los bosques más ricos en animales que desde siempre han sido base de su alimentación.

Las comunidades actuales no han perdido todos sus rasgos indígenas, pues una buena parte aún visten la cushma que es el traje tradicional; tienen como comida principal la yuca, sea cocida o asada, así como la patarashca, el empacado y la práctica de ahumar el pescado o la carne del monte. Ni qué decir del masato, la bebida tradicional que acompaña todos los momentos de la vida del ashéninka, o el uso del achiote en la pintura para las distintas ocasiones.

En el caso de la lengua, aún se habla ashéninka dentro de las comunidades en el ámbito familiar, aunque con la educación formal y otras influencias externas se va priorizando el castellano.

La agricultura es la tarea más importante actualmente, además de la caza y la pesca que aún practican; cultivan la yuca, presente en todo momento y de distintas formas: arroz, maíz, camote y algunos productos más de menor importancia. Toda la producción es principalmente para su consumo; el excedente de esa producción, junto a las gallinas, pescado o carne del monte que puedan tener, son llevados a la ciudad de Atalaya para venderlo y abastecerse con los productos básicos y necesarios dentro de su terreno: machetes, hachas, jabón, sal, frazadas, algo de ropa, así como alguna gaseosa, que suele ser el antojo en la comunidad.

La influencia externa se hace notar a distintos niveles. La educación formal, por ejemplo, impartida muchas veces en castellano, obviando la lengua propia; otras influencias externas son las empresas madereras y la vestimenta. Algo que a mi parecer está abriendo al pueblo ashéninka hacia el exterior es la salida de los jóvenes - en su mayoría varones, aunque también mujeres - a la ciudad de Satipo, donde son contratados para trabajar como jornaleros en la cosecha de café, coca o cacao. Esta situación se está convirtiendo como en un mandato para los jóvenes que sí o sí deben salir para "conocer el mundo y ganar su platita" y volver como mayores de edad y como quien ya ha sorteado los avatares de la vida. También debido a la salida a trabajar "revolcando" madera por varios meses, de donde regresan generalmente sin el sueldo que buscaban, pues son contratados como jornaleros y al estar en media selva le suministran implementos que son descontados de su sueldo, con lo que salen como entraron, o en su defecto simplemente no les pagan, con la excusa de siempre, "voy a sacar la plata del banco y te busco": al estar las comunidades, distante de la ciudad, es prácticamente trabajo perdido. 


\section{Cosmovisión ashéninka}

Se pueden encontrar, si uno busca con atención, muchos mitos que tratan de explicar el origen del universo, tales como la vida que brota en la tierra después de una inundación, o el poder transformador de Avireri o Navireri, que a su paso fue transformando a personas o grupos de personas en animales o plantas con lo que queda configurada la realidad conocida actualmente.

Sin embargo, quiero centrarme sobre la información dada por Luis Cushimariano y María Cajanto, dos indígenas ashéninkas que pasan los 50 años y son portadores del conocimiento y sabiduría indígena. El primero es Chamán ayahuasquero y la segunda curandera a través de vaporaciones y tiene un amplio conocimiento de plantas medicinales y su uso para la curación de las distintas enfermedades.

Siempre han creído en un Dios Padre, Creador, Todopoderoso, el Pawa Tajorentsi, como se le ha traducido; también en los espíritus del bosque, de las diferentes plantas y árboles, así como en la madre del agua, que viene a ser el espíritu del agua, representado de distintas formas. Del mismo modo se encuentra el dueño del monte y de los animales, conocido por algunos como el chullachaqui, encargado de cuidar los animales y castigar a quienes se sobrepasan en la caza, por ejemplo.

Los muertos no van no al cielo ni al infierno, pasan a otra dimensión, pero están entre nosotros. Están siempre entre nosotros y pueden comunicarse o manifestarse a los vivos a través de los sueños, como lo explica Luis Cushi, con naturalidad:

Los muertos están por acá nomás, entre nosotros, hacen su casa en los lugares que no se visitan, en las cochas, en las cuevas, pueden estar ahora escuchándonos. Nosotros no los vemos, pero ellos sí a nosotros, igual si es de día o de noche, porque para ellos todo es igual. Así mismo están siempre queriendo llevarse a las personas enfermas.

Todos estos espíritus del bosque, del agua y de los difuntos se interrelacionan con el ser humano y lo pueden afectar, causando enfermedades de distintos tipos.

Ante las enfermedades causadas por los espíritus está el chamán, figura representada principalmente en el ayahuasquero; quien cura con la ayuda de los espíritus de la naturaleza: tomando el jugo refinado de la soga llamada ayahuasca. Además, está el sheripiari, que cura con el tabaco, a través de distintas formas. También existen las vaporadoras, parteras y "curiosos"; que ayudan en la curación de las distintas enfermedades a través de la preparación de bebidas 
de distintas plantas o baños, también con plantas. Y no olvidemos al sobador, que se encarga de colocar los huesos en su lugar cuando alguien sufre alguna luxación o con el uso de plantas cuando es quebradura del hueso.

\section{Tipos de enfermedades desde la concepción ashéninka}

La realidad de la medicina en América Latina se caracteriza por la diversidad cultural que se da por la coexistencia de la cultura indígena y la occidental, donde, aunque la segunda se haya impuesto como dominante, la indígena no ha desaparecido. La desigualdad socioeconómica, dada principalmente por la concentración de poder en unos grupos pequeños, así como el control de la economía por parte de estos grupos, llevan a la minoría a sufrir la discriminación cultural, que conlleva además una discriminación medicinal.

Asimismo, la diversidad curativa es expresión de la diversidad cultural del continente, donde pueden atender los problemas de salud santiguadores, curanderos, chamanes, médicos, rezadores, enfermeras, predicadores, etc.

Recuerdo que cuando recién llegué a la zona me resultaba difícil entender por qué ante alguna enfermedad, no buscaban la posta médica o medicinas farmacéuticas, ya que supuestamente los síntomas indicados correspondían a enfermedades que posiblemente se curarían con un simple tratamiento medicinal.

Ahora entiendo aquello que cada pueblo ha desarrollado históricamente sus propias creencias, conocimientos, actitudes y prácticas alrededor de los problemas de salud-enfermedad.

La experiencia y cercanía al pueblo ashéninka me ha hecho ir entendiendo la clasificación que tienen de las distintas enfermedades y sobre todo saber que las enfermedades pueden ser naturales, causadas por algún espíritu o por mal de gente, la enfermedad causada por la brujería o hechicería.

\subsection{Enfermedades naturales}

Por enfermedades naturales se entienden aquellas enfermedades que atiende el médico del hospital, la enfermera o el promotor de salud comunitario, con el uso de medicinas de la farmacia o botica, por lo que se le denomina enfermedad de botica. Es muy común escuchar "esa enfermedad no es pa vegetales, no le hace caso, esa es pa la botica" o simplemente son "enfermedades de botica". Dentro de esta clasificación también entran las que se curan con plantas medicinales, o "vegetales", como se le denomina. 
En otros términos, son aquellas enfermedades biológicas que se curan atacando el componente biológico que está siendo afectado, sea por el uso de medicina tradicional o medicina occidental.

Entre las enfermedades más frecuentes de este tipo se puede encontrar: gripe, resfrío, fiebre, tos ferina o coqueluche - llamada también "muere muere" por la asfixia momentánea que se padece-, dengue, malaria o paludismo, bronquios o bronquitis, parásitos, infecciones internas y de la piel, neumonía, diarreas, vómitos, cólicos, entre otras menos frecuentes. Cada una de estas, con su matiz particular, por ejemplo, la gripe es más que una gripe simple como se conoce en la ciudad, la fiebre es otro mal complicado, ya que cuando les ataca es muy fuerte, el organismo no lo tolera con naturalidad, etc.

\subsection{Las "enfermedades de los espíritus"}

Las he titulado como enfermedades de los espíritus porque estas tienen que ver con el espíritu del enfermo o alguno de los espíritus que forman parte de la cosmovisión ashéninka.

\subsubsection{E1 susto}

El susto es una enfermedad común a muchos pueblos del continente, la he escuchado en la sierra como también en la Amazonía boliviana y por referencias, también en otros países del continente. Es también conocido como manchari.

Para el pueblo ashéninka, el susto se da principalmente en los niños. Los niños aún no están bien formados, su espíritu es frágil, se puede asustar con facilidad. Los adultos pueden asustarse, pero ese ya viene a ser otro tipo de susto. Jemner Gonzáles, curandero y huesero, lo define de la siguiente manera: "el susto es un mal del espíritu, de repente hay un panteón por ahí, ahí ha muerto una persona o le han enterrado, a veces pasan los niños y les choca el susto".

Otra forma de enfermarse del susto es cuando el niño o niña se altera por algún motivo, sea un ruido fuerte, se ha caído, ha sido expuesto a un ambiente que lo sobresalta, su espíritu se desacomoda o bien se sale de su cuerpo. También puede enfermarse porque la mamá que haya chocado con un espíritu, aunque a ella no la haya enfermado, le puede pasar al niño cuando le da de lactar.

Los síntomas del susto según el mismo informante son: "nosotros sabemos cuando el niño se asusta cuando va a dormir, a veces le agarra el vómito, fiebre, se revuelca, ya no puede dormir". Su curación tiene distintas formas, desde 
pasar el huevo para sacar el mal, hasta soplar con tabaco, además de baños con plantas entre otras formas de curación.

\subsubsection{Mal causado por "ver diablo", demonio o bulto}

Como en toda la humanidad, el bien y el mal están presentes dentro de la cosmovisión ashéninka. El mal, el diablo o demonio, peyari o kamari en lengua ashéninka, es la personificación del mal que se presenta a alguien de distintas formas; sea como una persona fallecida, un ser horrible, una persona que se desliza flotando etc., también puede presentarse como un familiar o conocido que ha fallecido.

He escuchado muchas historias donde ven a alguien que ha fallecido, pero solo medio cuerpo flotando, o el familiar fallecido esperando en el camino. Este fallecido puede aparecerse, aunque el fallecido haya estado en otra parte lejana, eso indica que es el demonio, diablo o peyari.

Ante tal experiencia, las personas se suelen enfermar con síntomas como la fiebre, sobresalto al dormir, pesadillas, pérdida de apetito, que deben ser tratados por especialistas en la materia a través de baños con plantas u otros secretos a través de plantas medicinales. Estos síntomas por alguien de fuera pueden asociarse fácilmente a la epilepsia; sin embargo, las formas de curarse son tradicionales e increíblemente efectivas.

\subsubsection{El malaire y choque de aire}

$\mathrm{El}$ malaire y el choque de aire, son muy parecidos, pero tienen su diferencia. Nuevamente recurriré a la información de Jemner, pues él es un especialista en el tema: "el choque de aire es uno solo, a los niños o grandes los puede desmayar, se siente un poco mal y proviene de un mal espíritu, del demonio (un difunto puede ser), o también de un espíritu malo; hay las dos clases, porque a veces hay espiritistas que hacen eso". El malaire "hay dos clases, de lluvia con el sol, del viento, de la cocha y también de los espíritus malos que hacen daño”.

Como puede concluirse, vienen a ser aquella enfermedades o males causados por la alteración del alma debido los males provenientes de distintos ámbitos, los difuntos, espíritus de los hechiceros o espiritistas, o por fenómenos naturales que tienen su ser sobrenatural.

Dentro de la concepción ashéninka, el espíritu del difunto queda acá entre nosotros, como un aire algo denso que puede abrazar a la persona $y$ 
enfermarla, hasta hacer que esta se muera, en la creencia indígena, "se lo lleva a su lugar del muerto".

Como puede verse, estas tres enfermedades del espíritu suelen ser muy similares, pero cada una requiere ser considerada según es, ahí está la sabiduría indígena que hace la distinción entre una y otra. Como elementos que la diferencian, podría citarse que por ejemplo el susto, afecta principalmente a los niños y puede ser causado además de malos espíritus, por fenómenos naturales como un ruido fuerte o una caída, además que puede ser curado por alguien de la familia que por tradición lo hace, sin otro conocimiento mayor. El susto, malaire y choque de aire, afecta a todas las personas, principalmente adultas y el tratamiento necesita ser hecho por alguien especialista que sabe cómo curarlos a través de plantas; e incluso atraer el alma del enfermo en caso de que el mal espíritu o el fenómeno natural la haya jalado.

\subsubsection{El cutipo}

El cutipo es otro mal que afecta principalmente a los niños recién nacidos, aunque puede darse el cutipo a personas adultas. Consiste en la transmisión de un mal al niño, este mal puede ser una característica de aquello que cutipa. Existen varias formas de cutipo, por la comida, por tocar un animal o planta e incluso existe el cutipo de la infidelidad.

Recurro nuevamente a Jemner, él dice: "nosotros como ashéninkas sabemos, cuando comes algo que no es, eso le cutipa al niño, le hace daño". Si el padre o la madre come ciertas comidas, el niño se va a enfermar, por ejemplo:

Si come carne de res, seguro se va a enfermar con diarreíta y no va a parar, si come mono, el niño va a llorar y hace como mono, si come ronsoco, va a silbar como ronsoco, si como el pescado dorado el niño va tener la piel como el dorado. También hay de planta; por ejemplo, de catahua: cuando pisas la hoja, el niño se va a enfermar; hay que llevar la misma hoja para hervirla en agua caliente y bañarle con eso para que le pase.

Existe otro tipo de cutipo, el de la infidelidad, cuando el niño se enferma, "su pecho suena, como bronquitis, cuando le hace el tratamiento el médico (naturista), dice que le ha cutipado su padre o su madre porque ha hecho cosa mal". Por gestos me hace entender que se trata de infidelidad. "Eso que suena en el pecho del niño es como el semen del padre o lo que ha recibido la madre", según quién haya cometido la infidelidad le pasa el daño al niño. 


\subsection{El mal de gente}

El mal de gente hace referencia a aquellas enfermedades o males provocados por el ser humano, o gente; principalmente por envidia o venganza. Aunque también con otros propósitos, como provocar otro tipo de conductas malas en la persona a la que se le hace el daño, provocando así algún tipo de sufrimiento.

\subsubsection{La hechicería}

La hechicería viene a ser el mal hecho a nivel espiritual a una persona por otra. En este caso, el hechicero, especialista en causar el mal. Usan la magia negra, la maldad y tienen el poder de hacer que la persona fallezca instantánea o lentamente.

Al hechicero "le ha ganado el mal", ha aceptado lo que le propuso el mal, como dice don Roger Núñez: "por eso ahora, como por instinto, puede hacer el daño o porque alguien le paga para que haga daño a otra persona por venganza, por envidia o simplemente por maldad también".

Los síntomas de este tipo de enfermedades pueden ser similares a los de una enfermedad natural, por eso muchas veces es tratada como tal. Por ejemplo, cólicos, dolores en alguna parte del cuerpo, especialmente el estómago — donde una especie de bulto se levanta y se mueve por encima de la piel-, hinchazón en las rodillas o pies, u otra parte del cuerpo sin otro rastro más. Sin embargo, cuando no se ve mejoría, cuando hay sueños extraños, entonces se recurre al chamán, curandero, médico o vegetalista especializado; él es el único que puede curar este tipo de enfermedades, dado que el mal es puesto por otro especialista, con maldad, a través de espíritus malos; por eso, requiere ser contrarrestado al mismo nivel.

\subsubsection{La brujería}

La brujería viene a ser parecida a la hechicería. Sin embargo, tiene un nivel menos avanzado que esta; la puede practicar cualquier persona que conozca un poco el tema, como lo explicaba Luis Cushi: "la brujería se hace por ejemplo enterrando huesos, espinas de pescado, clavos en tu patio de tu casa; eso entonces entra en el cuerpo de la persona y empieza a sentirse mal". Existen los brujos o brujas, pues según la tradición, la mujer puede aprender a ser curandera más rápido que el hombre; sin embargo, es también más fácil que se haga bruja, que 
empiece a causar las enfermedades, como por instinto, como algo que no puede controlar: de vez en cuando tiene que hacer el daño a alguien.

\subsubsection{La pusanga y el brebaje}

Con la pusanga y brebaje entramos a otra forma de causar mal o enfermedad. La pusanga son plantas, más bien pequeños arbustos, que con el uso de su raíz, su tallo o sus hojas, según el caso, se puede causar algún mal a las personas. Según se quiera hacer, por ejemplo, se puede frotar en las manos, y al saludar a la otra persona, pasarle aquello que se propone. A veces se prepara como perfume, incluso pasándole las hojas o la parte de la planta por el cuerpo o en la ropa u otro objeto personal, a través del cual puede ingresar el daño al cuerpo de la misma. Se puede causar también la "saladera", que es ponerle a la otra persona algo en el cuerpo para que todo le salga mal, para que sufra, etc. Cabe hacer notar que la pusanga también es buena, pues existe para cosas buenas: para la buena suerte, para el amor, para hacerse más atractivo a las mujeres u hombres, según el caso, para que alguien se enamore, para bloquear todo tipo de mal, etc.

El brebaje es también preparado de alguna planta que se da en la bebida, generalmente cuando se invita masato o comida, en ellos se pone la hierba y por la comida entra al cuerpo, causando el daño o mal al cuerpo. En ambos casos no resulta tan difícil curar, lo puede hacer el chamán u otros curanderos a través de baños con distintas plantas o vaporación.

\subsection{La importancia de los sueños en la salud}

Dedico a este tema una parte especial porque para el ashéninka los sueños son de vital importancia, pues a través de ellos se guía y recibe avisos de distinto tipo; en definitiva, los sueños son tan reales y parte de la vida misma, como lo puede ser la tecnología para quienes viven en la ciudad, pero a un nivel mucho más profundo.

Para mí ha sido todo un descubrimiento de esta dimensión y no deja de sorprenderme pese a que comparto mucho con ellos. He llegado a conectarme con esta forma de percibir el mundo, la parte de mi mentalidad occidental en muchos aspectos me hace sorprenderme ante tal experiencia.

Los sueños vienen a ser como el canal de comunicación entre el hombre, la naturaleza — con esto me refiero a animales, plantas, ríos, aves- con el 
mundo de los difuntos. Hay tal conexión que los sueños dicen verdades que son asumidas como tal en la vida cotidiana. El chamán, por ejemplo, domina los sueños, va más allá del común, dentro de los sueños puede viajar, transportarse de distintas formas, combatir el mal espiritualmente, pues el espíritu sale y se mueve a otro nivel, un nivel espiritual.

A través de los sueños, por ejemplo, se conoce qué tipo de enfermedad se tiene, o de dónde proviene; se puede saber quién es la persona que causa el mal. Se puede saber si el mal o enfermedad viene de un árbol, del río o por algo que ha comido, etc.

Cuando alguien está enfermo y duerme, sueña que sus antepasados o un familiar cercano muerto lo visita y lo invita a irse con ellos, a dejar de sufrir con la enfermedad.Y dentro de los sueños, si quiere seguir viviendo, debe evitar recibir lo que el muerto le invita, por ejemplo. De lo contrario, es seguro que se muere; también quien está curando a alguna persona de algún tipo de enfermedad no natural puede soñar al difunto que se lo quiere llevar.

\section{Dos experiencias: ante el choque de aire y curando el susto}

En esta última parte quiero presentar dos experiencias que me han tocado vivir; en ambas he sido no solo observador, sino parte activa, por eso las conozco más familiarmente.

\subsection{Ayudando a curar el choque de aire}

Esta primera experiencia ocurrió en una comunidad nativa. Llevé por tres días con sus noches, por un retiro espiritual, a un grupo de estudiantes del último año de secundaria a la comunidad nativa de Diamante Azul; eran alrededor de 50 personas, con profesores y algunas madres de familia. Llegamos un jueves por la tarde. El día viernes transcurrió con normalidad hasta llegada la noche, donde las chicas tuvieron algunas discrepancias; asunto normal en grupos adolescentes. Hubo un momento de confrontación que promoví para superar el momento saludablemente; hubo sentimientos encontrados, resistencias de ambas partes conflictuadas. Sin embargo, se llegó a buen puerto. Esto sucedió aproximadamente a las 7 pm., después de la cena.

Pasada media hora, me llaman porque Teresa, una adolescente que había sido parte del conflicto, se estaba desmayando. Estaba sentada en un banco de madera artesanal bajo un mango muy antiguo, en un lugar oscuro pues no hay luz eléctrica, además de la sombra del árbol. Me acerco con calma, con mi 
mente supuestamente conocedora de este tipo de situaciones: un compañero la tenía agarrada, ella lloraba y balbuceaba algunas cosas. Mi primera hipótesis: "berrinche de adolescente que quiere llamar la atención". Le hablo, pero no obtengo respuesta alguna que indicara que me escuchaba. Me acerco, le toco el rostro. Estaba endureciéndose; luego empezó a retorcerse, la recostamos en el pasto y al ver eso, hago llamar a Nora, la promotora de salud de la comunidad, que llega como un rayo. Recuerdo bien cómo llegó, miró cómo se retorcía y su diagnóstico certero: "Es choque de aire”. Le pregunto incrédulo: “¿Será?” Se agacha, le toca los pies, el vientre y nuevamente afirma: "sí, es choque de aire". Entonces pregunto sin saber qué hacer ante la situación: “¿Eso cómo se cura o que se hace?”. Me dice: "ahorita la vamos a curar". Luego mandó a uno de los muchachos de la comunidad por agua florida de donde la tía Graciela. Motivo también para que Graciela viniera en ayuda. Otros muchachos desaparecieron en la oscuridad mandados a traer piri piri y flor de tunche para choque de aire. En pocos minutos, ellos ya estaban con las plantas.

Ahí, sobre el pasto, Teresa se retorcía. Tenía una fuerza algo más de lo normal y decía una y otra vez: "No me lleven; déjenme; no me quiero ir; déjenme". Entre cuatro compañeros suyos la agarraban y ella se retorcía y estremecía repitiendo lo mismo una y otra vez. Nora y Chela empezaron a curar: Nora frotaba todo el cuerpo de Teresa con agua florida y con la flor de tunche, Graciela masticó las hojitas del piri piri y en su blusa lo escupía luego para exprimir ese jugo y hacerlo caer al ojo de la afectada. Me dijo, "es picante esto", al tiempo que escupía a un lado por lo picante: "Si es mentira ahorita va a saltar porque pica más en la vista; ahorita vamos a saber”.

"Usted tiene su cashimbo (pipa para fumar tabaco puro); ahí fúmela pa ayudar a sacarle el mal espíritu”, me dijo Graciela. En ese ambiente de curación comunitaria, me puse a fumar y soplarle con tabaco, uniéndome a la curación, como limpiándola; algo ya sabía sobre ello. Algo dentro de mí esperaba que al sentir el picante en la vista, Teresa reaccione; pero no fue así a la primera vez. Después de un rato, otra vez, y la tercera vez, recién reaccionó un poquito haciendo notar que sentía algo en la vista. Hasta eso, ya habría pasado casi una hora.

Poco a poco se fue calmando, reaccionando. Entonces la llevamos al botiquín comunal, donde ya se repuso del todo. Era las $11 \mathrm{pm}$ cuando ya habló normalmente. Pidió algo para comer, señal de que se había recuperado. Entonces se formó un ambiente de alegría, recién empezaron todos a acordarse de lo que pasó en el momento de apuro. Anécdotas de uno y otro tipo, algo tan característico de la zona. 
Aún incrédulo, a ella le pregunté en plan de confianza: qué pasó, porqué se puso así. Pero que me dijera la verdad, que no me mintiera. Lo que me contó fue lo siguiente:

Después que acabamos de hablar yo fui enojada todavía y me senté solita ahí debajo del mango, y sentí un viento frío que me hizo estremecer mi cuerpo y después de un ratito ya me empecé a sentir mal, y no me acuerdo mucho de lo demás hasta que desperté aquí en la cama.

Insistí: “Por qué decías que no te querías ir, que no te lleven, si nadie te iba a llevar? "Si le digo no me va a creer", me dice. "Cuéntame nomás; a ver, ¿qué era? Entonces me dijo:

Yo veía una mujer que venía hacia mí caminando y cuando se acercaba parecía que su ropa se iba cayendo y se hacía como una calavera, y mandaba unas, como calaveritas, puro huesos que me jalaban y querían llevarme, por eso era que yo me hacía así y decía que no me lleven, porque me iban a llevar.

Fue una conversación privada, de esto el resto no se enteró. Preferí decir al resto del grupo que fue un ataque de nervios para no causar conmoción. Después la acompañé al ambiente donde dormían las chicas.

Yo dormí en ese botiquín comunal, solo. Cuando estaba empezando a dormir había un ave nocturna por alrededor de la caza, se le escuchaba. Después de un rato se oyeron unos pasos que se acercaron a la puerta, pues en realidad no había puerta y es terreno arenoso, se escuchan bien, eran pasos de mujer, eran más suaves y cortos, con diferencia se reconoce si es hombre o mujer. Quedé escuchando, entró un poco, se paró, al menos eso parecía por los pasos, luego se retiró.

Al siguiente día, a la hora del desayuno visito a Nora para conversar sobre el asunto, pues es común al amanecer conversar acerca de lo que se ha soñado. Le pregunto ¿Y qué tal has dormido? Me dice: "Ay, no he podido dormir. Mi suegra me ha molestado. Era ella la que quería llevarse a la chica. Vino y me dijo por qué me tengo que meter yo, por qué no la dejo, y he luchado con ella”. Su esposo, José María, me dice: "Sí. Me ha dado unos puñetes durmiendo. He tenido que despertarla pa que no se la lleve mi mamá a ella en vez de la chica”. Su suegra ha muerto hace unos años.

Le comento de lo que había escuchado por la noche y me explican: "Ah, era ella entonces que quería insistir buscando a la chica. Como la llevamos ahí al botiquín, ahí fue a buscarla, pero se habrá asustado al encontrarlo a usted y vino contra mí”. 
La parte racional-occidental se planteó muchas posibles explicaciones al asunto, tratando de negar lo sucedido. Sin embargo, dado el hecho, dada la realidad tan natural de este tipo de situaciones, me ha llevado a abrirme a conocer y entender este tipo de "enfermedades" y cómo se abordan situaciones desde otras formas que muchas veces son menospreciadas en la modernidad.

\subsection{Soplando para curar el susto}

El susto es un mal que ataca a los niños principalmente; ellos siempre estarán propensos al mal de susto mientras su cuerpito y su espíritu no estén bien formados.

Tengo cierto cercanía y experiencias con dos chamanes del lugar, poco a poco me han ido enseñando los secretos para curar ciertas enfermedades o males; los más simples por supuesto, uno de ellos el susto.

En el apartado de las enfermedades ya se ha hablado del susto, sin embargo, quiero hablar de mi propia experiencia: primero, quienes identifican el susto son los padres o familiares del niño y buscan quién pueda curarlo. Los principales síntomas con los que he encontrado son diarrea (tipo infección), fiebre, ojos hundidos, palidez; los niños no pueden dormir o se sobresaltan cuando duermen. A simple vista estos síntomas son los de una infección común y corriente; sin embargo, cuando se trata de curar con medicinas de la farmacia no les hace efecto, ni siquiera la ampolla o inyección.

Una de las formas de curar el susto, me enseñaba el maestro Luis Cushi, es soplando con tabaco el cuerpo del niño asustado; principalmente en algunos puntos vitales como el estómago, la corona, la planta de los pies.

El proceso de curación es el siguiente: se inicia conversando con los padres, preguntando de dónde creen que viene el susto, si se ha caído, algún ruido extraño o ha quedado solo, o tal vez por el monte ha estado y algún espíritu le ha jalado su alma. Una forma de saber si es susto o infección es tocando el pulso en la muñeca del niño o niña; el pulso refleja el latido del corazón y hay una pequeña diferencia que se percibe, el latido puede ser normal, incluso algo lento; pero cuando es lento y continuado, algo sutil, entonces es algo anormal.

Antes de soplar se debe tragar tres aspiradas de humo para evitar que el susto o mal que tenga pase al que está curando, luego se le hace tres cruces, porque tres fueron las cruces cuando crucificaron al Señor Jesús. Y se empieza a soplar todo su cuerpo, pero principalmente el estómago, la espalda y la 
cabeza, en la corona. En todo momento pidiendo a Dios la curación del niño enfermo. El tabaco tiene una importancia vital para este pueblo, espanta cualquier espíritu malo, serpientes; puede controlar el mal tiempo, entre sus principales características, a esta se le añade el de curar.

La soplada, así como la chupada, es una técnica de curación muy común entre los ashéninkas y en muchas partes de la Amazonía; ambas técnicas se realizan con el tabaco, y para tratar de traducirlo, podría decirse que a través de ellas los médicos curanderos, sheripiaris, incluso algunos curiosos, a través del soplido y con ayuda del tabaco, trabajan en restablecer el orden del cuerpo energético del niño o la persona enferma. Al soplido se experimenta una especie de fricción energética que desgasta a quien cura, por eso no lo hace cualquier persona. La combinación entre el rezo, la invocación a los santos a la virgen María y el uso de elementos propios como el tabaco, piñón morado, mucura, alcohol, crean todo un ambiente y un momento de profunda espiritualidad que restablece la salud de los enfermos.

Es difícil poner en palabras los pormenores de estas experiencias, no se llegan a abarcar, la palabra no expresa la profundidad de esta forma de curación tradicional. Esta puede ser una de las razones por las cuales nuestros pueblos amazónicos no han necesitado la escritura, dado que las experiencias profundas, como cultura, han ido pasando de generación en generación, pero a través de experiencias profundas, que marcan la vida y quedan grabadas en el interior mismo de la persona que se encuentra abierta a interrelacionarse con la naturaleza y Dios. Me resulta tan sorprendente la naturalidad con la que se realizan las curaciones, así como su efectividad, puesto que la mayoría de tratamientos que se realizan acaban sanándose.

Esto es algo tan natural para este pueblo como que el sol da luz, algo que, aunque viva con ello, muchas veces me resulta difícil de asumir como tal, pues la parte intelectual, hace que, aunque lo haya experimentado, busque darle una explicación lógica, algo difícil de hacer desde experiencias tan profundas como las amazónicas. 


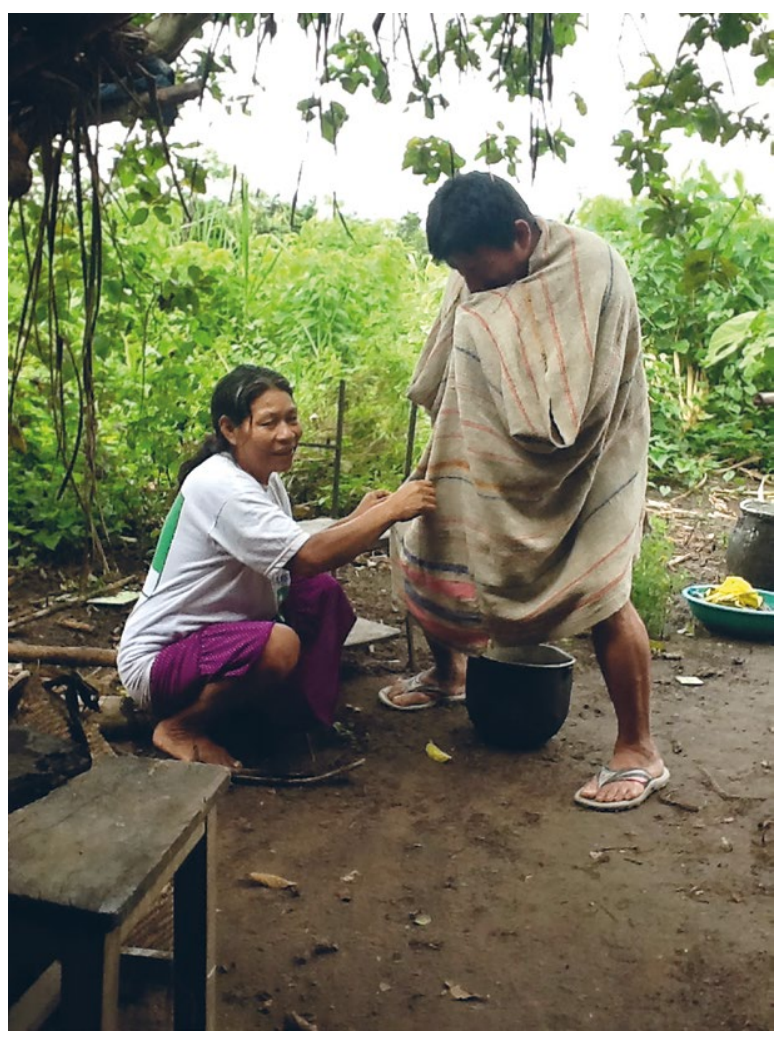

Curación con vapor que realiza María Cajanto Faman.

\section{Conclusiones}

El cuidado de la salud es uno de los pilares de la sociedad, más en los pueblos indígenas como el ashéninka, donde la salud se concibe no solo como ausencia de enfermedad, sino como el equilibrio en las relaciones con los espíritus, con la comunidad humana y los difuntos, un equilibrio que permite llevar una vida según su propia cosmovisión.

Desde esta forma de entender es que se aborda la enfermedad y los males, a través de distintas técnicas y con el uso de plantas y elementos de la naturaleza conservados ancestralmente y con los cuales se restablece la salud.

El pueblo ashéninka no es muy conocido como tal, ha sido asumido hasta hace poco por los estudiosos y el Estado peruano dentro del pueblo asháninka; motivo por el cual se requiere profundizar en todas sus dimensiones, puesto que, aunque ellos son conscientes de su familiaridad con los asháninkas, se diferencian incluso de palabra como ashéninkas. 
La cosmovisión ashéninka parte de un Dios Padre Todopoderoso, el Pawa Tajorentsi, que crea el mundo y parte de esta creación son los espíritus de la naturaleza, sean del agua, del aire, de la tierra, las plantas y animales; así como dentro de esta misma realidad se encuentra el alma de los difuntos que pueden afectar de forma negativa a los vivos. La salud se mantiene por ese equilibrio entre el ser humano y los espíritus de la naturaleza, de los difuntos, y las distintas formas de curandería. Cuando alguna de estas formas altera el equilibrio, proviene la enfermedad y se recurre sobre todo al médico ayahuasquero, vegetalistas, curiosos, para que restaure este equilibrio a través de distintos métodos.

La armonía cuerpo-alma o espíritu, no es la dualidad cuerpo malo y alma buena, propia del cristianismo clásico, sino que esta garantiza la buena salud, puesto que si el cuerpo enferma afecta todo el ser, pudiendo ser presa fácil de los difuntos; o, por el contrario, si el alma es afectada causa la enfermedad del cuerpo, lo debilita y lo puede llevar a la muerte también. Existe una interdependencia tal que uno no es más importante que el otro.

La dimensión espiritual esta bien desarrollada, no solo como capacidad para percibir lo sobrenatural, sino también para acceder a otra dimensión de la realidad a través de los sueños, la ayahuasca o el tabaco, y desde esta dimensión poder curar o restaurar el equilibrio necesario para la vida.

Las principales enfermedades son las causadas por los espíritus o al espíritu de la persona, por lo que la principal atención es brindada por los chamanes, vegetalistas, curanderos o curiosos que tienen esa capacidad; además que lleva al uso de plantas medicinales por encima de la medicina occidental. Esa razón, además del mal trato del que son víctimas en los centros de salud, puede ser una razón por la que no se recurren en el hospital de la ciudad o posta médica, a no ser en caso extremo.

\section{Términos locales}

Achiote: planta y fruto de un arbusto con semillas color rojo que pueden ser usadas para pintura corporal, tejidos o cerámica. En Bolivia se le conoce como urucú.

Ayahuasca: bebida tradicional elaborada en base a la soga o liana del mismo nombre, bajo su efecto el médico ayahuasquero puede realizar curaciones en estados ampliados de conciencia con la guía de las plantas maestras y la ayuda de los espíritus de la naturaleza. 
Cashimbo: pipa artesanal para fumar tabaco puro.

Cushma: túnica amplia, originalmente tejida de algodón, con abertura para cuello y brazos que usan hombres y mujeres del pueblo ashéninka y asháninka en general, con sus propias variaciones.

Empakado: comida preparada, sea de carne o pescado, en un pedazo de bambú, llamado paka.

Flor de tunche o rosaciza: flor, tipo margarita, color naranja, que se encuentra sobre todo en los cementerios o alrededores.

Masato: bebida fermentada, elaborada a base de yuca que acompaña todo momento de la vida del indígena, como refresco o como bebida para fiesta.

Patarashka: comida preparada a base de carne del monte o pescado en hojas de una planta que crece al lado de las quebradas.

Peyari: diablo o demonio en lengua ashéninka.

Piri piri: variedad de pasto, cuyas raíces en forma de papas pequeñas, según la cosmovisión ashéninka, tienen propiedades medicinales a nivel biológico y espiritual.

Pusanga: planta con la cual se puede introducir en una persona el daño o, por el contrario, lograr ciertos efectos positivos.

Saladera: mal que se encuentra en el cuerpo de la persona y hace que todo le salga mal; sea trabajo, salud, relaciones interpersonales, etc.

Tunche: según la mitología popular, es un ser que vaga por las noches, o también puede significar el alma de un difunto que vaga por las noches.

Vegetalista: conocedor y practicante de las propiedades medicinales de distintas plantas que utiliza junto a rituales. 


\section{Informantes}

Jose María Mourao Arias, 54 años, natural de Diamante Azul.

Jemner Gonzales Suárez, 42 años, de la comunidad nativa San Elena de Yanayacu. Conocedor de plantas medicinales y de su uso.

Luis Cushi Mariano, 58 años, médico ayahuasquero de la comunidad indígena Unini Cascada.

María Cajanto Faman, 57 años, de la comunidad nativa Diamante Azul. Vaporadora y conocedora del uso de plantas medicinales.

Róger Núñez Mourao, 62 años, natural de la comunidad nativa Diamante Azul. 